\title{
CLEANING THE LARYNGOSCOPE BLADE
}

\author{
ROBERT B. ROBERTS, M.D., F.F.A.R.C.S. (ENG.) *
}

That an ANAEsthetist should use clean equipment, even if it is not sterile, is surely a tenet with which none would argue.

The laryngoscope, when introduced into a patient's mouth and pharynx, occasionally produces trauma or lies near traumatized mucosa. An unsterile laryngoscope blade could introduce potential pathogens into the pharynx and from there into the tracheo-bronchial tree. Many different methods are used to try to sterilize laryngoscope blades. Probably the least frequently used, yet the most effective, is autoclaving. This short survey was undertaken to determine the efficacy of some commonly used methods of cleaning.

\section{METHOD}

Bacteriological swabs from 24 laryngoscope blades were cultured on to blood agar immediately following laryngoscopy and again following cleansing. They were divided into four groups of 6 each according to the method of cleansing used.

Group A: After use the laryngoscope blade was well washed with sterile gauze under a running tap with warm water at $120^{\circ} \mathrm{F}$ and dried with sterile gauze.

Group B: The blade was scrubbed well with a brush impregnated with Iodophor and detergent, rinsed with warm tap water and dried with sterile gauze.

Group C: The blade was wiped thoroughly with 70 per cent Isopropyl alcohol after use and then was dried with sterile gauze.

Group D: In this instance the blade was wiped with sterile gauze under a running tap and then was autoclaved.

Four other laryngoscope blades, chosen at random, were cultured after standing on the shelf overnight.

\section{Results}

The results are shown in Tables I, II and III.

The autoclaved blades showed mixed bacterial growth immediately after laryngoscopy, but were all sterile after autoclaving. The four blades taken from the anaesthetist's shelf before the first use of the day, when cultured grew:

Blade 1 Neisseria Catarrahalis

Blade 2 Neisseiria Catarrahalis, Non-haemolytic streptococci, Streptococcus Viridans and Diphtheroids

Blade 3 Staphylococcus Albus and Enterococcus

Blade 4 Diphtheroids

"Mount Sinai School of Medicine of The City University of New York.

Canad. Anaesth. Soc. J., vol. 20, no. 2, March 1973 
TABLE I

Cultures Obtained From laryngoscope Blades ImMediately After Intubation and After Cleaning With Warm Water

\begin{tabular}{|c|c|c|}
\hline & $\begin{array}{c}\text { Culture } \\
\text { Immediately after } \\
\text { laryngoscopy }\end{array}$ & $\begin{array}{c}\text { Culture } \\
\text { Immediately after } \\
\text { cleaning }(A)\end{array}$ \\
\hline 1 & Streptococcus Viridans & Strep. Vir. \\
\hline 2 & & \\
\hline & Non-haemolytic streptococcuss & $\begin{array}{l}\text { Non-haemolytic strep } \\
\text { (light growth) }\end{array}$ \\
\hline 3 & $\begin{array}{l}\text { Neiss. Cat. } \\
\text { Strep. Vir. } \\
\text { Diphtheroids }\end{array}$ & $\begin{array}{l}\text { Neiss. Cat. } \\
\text { Strep. Vir. } \\
\text { Diphtheroids }\end{array}$ \\
\hline 4 & $\begin{array}{l}\text { Strep. Vir. } \\
\text { Neiss Cat }\end{array}$ & $\begin{array}{l}\text { Strep. Vir. } \\
\text { Neiss. Cat }\end{array}$ \\
\hline & Non-haemolytic strep. & $\begin{array}{l}\text { Ness. } \\
\text { Diphths. }\end{array}$ \\
\hline 5 & $\begin{array}{l}\text { Strep. Vir. } \\
\text { Diphths. } \\
\text { Strep. Vir. } \\
\text { Klebsiella }\end{array}$ & No Growth \\
\hline 6 & $\begin{array}{l}\text { Staphylococcus Aureus } \\
\text { Strep. Vir. }\end{array}$ & $\begin{array}{l}\text { Staph. Aur. } \\
\text { Strep. Vir. }\end{array}$ \\
\hline
\end{tabular}

TABLE II

Cultures Obtained From Laryngoscope Blades ImMEdiately After InTUbation and After Cleaning With an IOdophor and Detergent SCRUB

\begin{tabular}{|c|c|c|}
\hline & $\begin{array}{c}\text { Culture } \\
\text { Immediately after } \\
\text { laryngoscopy }\end{array}$ & $\begin{array}{c}\text { Culture } \\
\text { Immediately } \\
\text { after } \\
\text { cleaning (B) }\end{array}$ \\
\hline 1 & Streptococcus Viridans & No growth. \\
\hline 2 & $\begin{array}{l}\text { Neiss. Cat. } \\
\text { Non-haemolytic Strep. }\end{array}$ & Staph. Albus \\
\hline 3 & $\begin{array}{l}\text { Beta-haemolytic strep. } \\
\text { Strep. Vir. }\end{array}$ & No growth. \\
\hline 4 & $\begin{array}{l}\text { Strep. Vir. } \\
\text { Neiss. Cat. } \\
\text { Staph. Aureus }\end{array}$ & $\begin{array}{l}\text { Strep. Vir. } \\
\text { Neiss. Cat. } \\
\text { (light growth) }\end{array}$ \\
\hline 5 & $\begin{array}{l}\text { Strep. Vir. } \\
\text { Neiss. Cat. }\end{array}$ & $\begin{array}{l}\text { Strep. Vir. } \\
\text { Neiss. Cat. } \\
\text { (light growth) }\end{array}$ \\
\hline 6 & $\begin{array}{l}\text { Strep. Vir. } \\
\text { Diphths. }\end{array}$ & $\begin{array}{l}\text { Staph. Alb. } \\
\text { Diphths. }\end{array}$ \\
\hline
\end{tabular}

\section{Discussion}

Wiping with 70 per cent isopropyl alcohol was the best cold cleansing method used in this study, although not entirely effective. Simple washing with warm water was most ineffective, in two cases serving only to bring other organisms out of the crevices! A commonly used disinfectant and detergent mix was also ineffective. Autoclaving, which is proven efficient, does not affect the bulb or wiring and should be used. It is realized that endotracheal tubes are passed through the 
TABLE III

Culture Obtained From Laryngoscope Blades ObTaINed ImMEdiately AFter INTUBATION AND IMMEDIATELY AFTER Cleaning with a 70 Per Cent Isopropyl ALCOHOL WIPE

\begin{tabular}{|c|c|c|}
\hline & $\begin{array}{c}\text { Culture } \\
\text { Immediately after } \\
\text { laryngoscopy }\end{array}$ & $\begin{array}{c}\text { Culture } \\
\text { Immediately after } \\
\text { cleaning (C) }\end{array}$ \\
\hline 1 & $\begin{array}{l}\text { Strep. Vir. } \\
\text { Diphths. } \\
\text { Klebsiella }\end{array}$ & Strep. Vir. \\
\hline 2 & $\begin{array}{l}\text { Strep. Vir. } \\
\text { Neiss. Cat. } \\
\text { Escheiria Coli }\end{array}$ & No growth. \\
\hline 3 & $\begin{array}{l}\text { Strep. Vir. } \\
\text { Neiss. Cat. } \\
\text { Diphths. }\end{array}$ & No growth. \\
\hline 4 & $\begin{array}{l}\text { Strep. Vir. } \\
\text { Neiss. Cat. } \\
\text { Klebsiella }\end{array}$ & $\begin{array}{l}\text { Strep. Vir. } \\
\text { Neiss. Cat. } \\
\text { Klebsiella }\end{array}$ \\
\hline $\mathbf{a}$ & $\begin{array}{l}\text { Strep. Vir. } \\
\text { Neiss. Cat. } \\
\text { Diphths. }\end{array}$ & No growth. \\
\hline 6 & $\begin{array}{l}\text { Strep. Vir. } \\
\text { Neiss. Cat. } \\
\text { Klebsiella }\end{array}$ & No growth. \\
\hline
\end{tabular}

bacteria laden mouth and pharynx, past the barrier of the vocal cords into the sterile trachea. Sterile tubes should be used and this manoeuvre is acceptable on the grounds that at most the patient's tracheo-bronchial tree is being contaminated only by his own commensals. Anaesthetists must decide their own role in patient protection but should be aware through numerous recent publications, ${ }^{1-4}$ that the onus is on them to guarantee bacteriological safety for their patients.

\section{SUMMARY}

Twenty-four laryngoscope blades were bacteriologically cultured immediately following laryngoscopy and again following cleansing. They were divided into 4 groups according to the cleansing method used:

Group A Warm water

Group B Iodophor and detergent

Group C Isopropyl alcohol

Group D Autoclave

Autoclaving was the only method which sterilized all the blades. Isopropyl alcohol was the best cold method, but was not 100 per cent effective. Autoclaving the laryngoscope blade after each use is recommended.

\section{RÉSUMÉ}

Sur 24 lames de laryngoscope, nous avons fait des cultures bactériologiques immédiatement après usage de la lame pour laryngoscopie et immédiatement 
après le lavage de la lame, nous avons fait quatre groupes, selon la technique du lavage:

Groupe A: Eau chaude

Groupe B: Iodophor et détergent

Groupe C: Alcool isopropylique

Groupe D: Autoclave

La technique à l'autoclave est la seule qui stérilise toutes les lames. Parmi les techniques à froid, l'alcool isopropylique était la meilleure, mais n'était pas efficace à 100 pour cent. Nous recommandons de stériliser à l'autoclave les lames de laryngoscope après chaque usage.

\section{REFERENCES}

1. Editorial: Cross-infection during anaesthesia. Brit. J. Anaesth. 36: 464 (1964).

2. Thomas, E.T. The sterilization dilemma: where will it end? Clinical Aspects. Anesth. \& Analg. 47: 657 (1968).

3. Roberts, R.B. The eradication of cross-infection from anesthetic equipment. Anesth. \& Analg. 49: 63 (1970).

4. Roberts, R.B. (Ed.) Infections and sterilization problems. International Anesthesia Clinics. Boston. Little Brown \& Co. Vol. 10, No. 2 (1972). 